\title{
Analysis of Sound and Meaning in the Song of the Happy Shepherd
}

\author{
Li Zhang ${ }^{1}$, Yuanyuan $\mathrm{Li}^{2 *}$ \\ ${ }^{1}$ Professor in School of Foreign Languages, North China Electric Power University, NO 689 Road, North District, Baoding, Hebei, China \\ ${ }^{2}$ Graduate Student in School of Foreign Language, North China Electric Power University, NO 689 Road, North District, Baoding, Hebei, China
}

DOI: $10.36348 /$ sijll.2020.v03i12.001 $\quad$ | Received: 19.11 .2020 | Accepted: 03.12.2020 | Published: 05.12 .2020

*Corresponding author: Yuanyuan Li

\section{Abstract}

The sound in the poem is not a decoration, but an important way to convey the meaning and a communicative skill that directly affect readers. Sound and meaning complement each other and coordinate with each other to better convey the thought of poetry. Yeats is one of the greatest poets of the twentieth century. His creation covers a wide range and he has always been the focus of academic circles. This article attempts to take Yeats' early work The Song of the Happy Shepherd as an example to explore the connection of sound and meaning of Yeats' poems from both its content and form. The relation between sound and meaning in a poem is like the relation between music and dance, harmonious matches enhancing each other. Sound enables to the expression of the meaning of poems. It plays an essential role to research the function of sound in the poem and contributes to have a deeper understanding of Yeats.

Key words: Sound; meaning; Yeats; poem.

Copyright (C) 2020 The Author(s): This is an open-access article distributed under the terms of the Creative Commons Attribution 4.0 International License (CC BY-NC 4.0) which permits unrestricted use, distribution, and reproduction in any medium for non-commercial use provided the original author and source are credited.

\section{CHAPTER-1 INTRODUCTION}

Scholars and experts have been more inclined to words than sound in researches on poetry for a long time. To some extent, it has led to false understanding and misunderstanding of poetry. The famous British poet and critic Pope [1] has said that "Sound should be an echo of meaning". There are various elements of sound in poetry which enrich the musicality of poetry, deepen the auditory effect and improve the transmission of meaning in poetry, including rhythm, light and accent, rhyme, sentence pattern, pause and so on. As poetry is characterized by its vocal performance, the interaction between sound and meaning is an indispensable part of poetic aesthetics. The relation between sound and meaning in a poem is like the relation between music and dance, harmonious matches enhancing each other.

Yeats is a famous Irish poet and playwright who won the Nobel Prize for Literature in 1923. His poems have gone through the romantic, aesthetic and modern periods of the British poetry and have undergone several changes to smelt a unique style. Poems of Yeats, especially early poems, mostly focus on the description of nature and the construction of a beautiful pastoral world which conveys Yeats's yearning for nature and harmony between man and nature.
In the poem The Song of the Happy Shepherd, the poet intends to use the shepherd to mourn the passing of simple and harmonious traditions and natural scenes. Yeats lives in the ear of technological development and the rise of the industrial revolution. Industrial civilization does not respect and protect nature, however, regards nature as the object of conquest. Due to the over-exploitation of nature by mankind, the ecological balance is broken and man and nature present a state of the opposition. The poet can only expresses the disappointment and helplessness through verses. Therefore, this article pay attention to explore the interaction and harmony of sound and meaning in Yeats's poems from the perspective of content and structure,

\section{CHAPTER-2 SOUND AND MEANING FROM THE PERSPECTIVE OF CONTENT}

There are various sounds in the poem so that this article is divided into two aspects: content and form. The content of the sound includes the use of word, rhyme and so on. In the poem The Song of the Happy Shepherd, Yeats uses the image of a shepherd to express his condolences for the dead nature. The poem is titled with "Happiness", but its thought is not happy. The poet intends to use the shepherd to mourn the passing of simple and harmonious traditions and natural scenes. The following will analyze the function of sound in conveying the meaning of the poem. 


\subsection{Vowels and consonants}

First and foremost, the first ten lines of this poem describe the poet's helplessness and disappointment in the real life. At that time, it was a period of prosperity for the development of technology and industry would inevitably lead to the destruction of nature [2]. There are 141 consonants and 82 vowels in the first ten lines. Generally speaking, when vowels are pronounced without being obstructed by airflow, they are harmonic sounds; while consonants are relatively sharp and harsh, they are dissonances. It will further convey the poet's aversion to the ugliness of urban industrial civilization and lament of the lost nature with so many consonants.

The internal situations of vowels and consonants are different. The poem contains more short vowels than long vowels. Short vowels are not as round and bright as long vowels and diphthongs. And their duration is short so that they can indicate a tense and depressed atmosphere. The use of "-oo-" in lines "The woods of Arcady are dead", "Words alone are certain good", "Word be-mockers-By the Rood", "By the stammering schoolboy said", "Nor seek, for this is also sooth", such as "woods", "good", "Rood", "schoolboy" and "sooth" makes it easier to create the atmosphere of sadness and pain. Additionally, the poet also uses the blasting sounds $/ \mathrm{d} /$ and $/ \mathrm{k} /$ to echo the "dead" at the beginning "The woods of Arcady are dead", which lays the melancholy and disappointing tone of the whole poem and creates a dull and solemn atmosphere. At the same time, it forms a strong contrast with the title "Happy", highlighting the theme of the poem.

\subsection{Onomatopoeic words}

Poets often choose words that can convey their meaning. The most direct one is onomatopoeic words which are divided into basic onomatopoeia and secondary onomatopoeia. The former refers to some voice to simulate human, animal and other sounds in nature. The latter is relatively obscure and part of the pronunciation of the word is related to a certain meaning. For example, "-i-" is often associated with "small", such as inch, thin, little, bit, etc.

In the poem The Song of the Happy Shepherd, both basic onomatopoeia and secondary onomatopoeia are used. In the twentieth line "In clanging space a moment heard", "clanging" which belongs to the basic onomatopoeia vividly reflects the sadness of the burning earth in the eyes of the poet. Although there is only one basic onomatopoeia used in this poem, secondary onomatopoeia is used many times in the poem to make it effectively convey thoughts and enhance the auditory effect of the poem. For example, "humming" and "echo-harbouring" in "Go gather by the humming sea" and "Some twisted, echo-harbouring shell" make the image of "sea" more vividly.

\subsection{Rhyme}

Rhyme in poetry is a very common way to express and an effective writing technique. Rhyme means the same or similar pronunciation between words and sentences, which constitutes the periodic repetition of sounds to enhance the musicality of poetry. Rhythm and sound cooperate to produce what we call the music of poetry. This music may serve two general functions: it may be enjoyable in itself, or it may be used to reinforce meaning and intensify the communication [3].

The expression of the sound through rhyme will have slightly different meanings to different readers. Rui Yuping [4] once mentioned that the alliteration, end rhyme and rhyme step of each poem have the characteristic of objective. Readers can basically reach a consensus as long as they have mastered the terms and concepts of poetry. The understanding of the interactive relationship between the sound and meaning of poetry has individual differences and intuitive colors, which provides a more intense research field for poetry analysis.

In the first six lines of this poem, the end rhyme of /d/, /i/ and the high frequency of /d/ improve the musical sense of the poem. What's more, the unique charm and sense of power of the poem are greatly enhanced, which gives readers a rapid impression. At the same time, the popping sound /d/ in "dead", "dreary", "dusty" is to some extent connected with dark and gloomy atmosphere. The alliteration in the poem mainly includes dreary/dancing in "In dreary dancing past us whirled", stammering/schoolboy in "By the stammering schoolboy said" and dusty/deeds in "Then nowise worship dusty deeds". And the continuous repetition of the consonants /d/ and /s/ also creates a sense of confusion in the impact sound. It echoes the content of the poem so that the sound and meaning are matched with each other.

In general, the use of vowels and consonants, onomatopoeic words and rhyme make Yeats's poem better to convey the meaning of the poetry. The highfrequency use of consonants, the imagination created by onomatopoeic words and the sense of rhythm can infer that such sounds are suitable for lamenting or expressing serious thoughts. It is a manifestation of the inner contradictions and the pain of the poet. The beauty of the past no longer exists and what is left is the scars caused by the industrial civilization. The poet seems to try his best to struggle in the poetry and sigh in his thoughts.

\section{CHAPTER-3 SOUND AND MEANING FROM THE PERSPECTIVE OF STRUCTURE}

The structure of poetry includes pauses, division of stanzas, arrangement of words and sentences. These seem to be irrelevant, but there are rules to follow, which are worthy of our attention and analysis. Different permutations and combinations 
inevitably highlight different meanings of poetry. For example, the sound effects of long lines of poetry are often long and the sound effects of short lines of poetry are often short and light. In the following part, this poem "The Song of the Happy Shepherd" will be analyzed from two perspectives: speed of the poem and arrangement of words and sentences, which contributes to explore the echoes of sound and meaning in Yeats's poems.

\subsection{Speed of the Poem}

The speed of poetry is composed of pauses, light and stress, and the use of symbols. A line of poems with the same syllable often has a slower rhythm due to the more stress. And it can speed up the rhythm to increase weak syllables. The fast speed is suitable for expressing emotions, such as tension, excitement, panic and anger; while the slow speed often expresses emotions of leisure, depression, disappointment and sadness.

The poem The Song of the Happy Shepherd uses the iambic tetrameter and trochees. The continuous repetition of light and stressed syllables creates a rhythm sensation. Sometimes a few weak syllables enhance the effect of sound flow. The sound changes from weak to strong and then from strong to weal, which establishes an effect that is full of change and flow.

In addition, the whole poem is composed of short lines which lead to the information gaps. These gaps can only be filled by the form of poetry and images in the poem. Information in the form of poetry includes dashes, writing styles, pauses and so on. In the poem, the use of three dashes "Word be-mockers-by the Road", "The whirling ways of star-bane" also stimulates readers' imagination, gaining the new vitality in the poem. The function of the dash is to emphasize content in order to enhance the rhythm of the poem. These dashes also increase the blankness of the poem, which can be connected with the nostalgia for nature. The poet still has a glimmer of hope in his disappointment, trying to rebuild the pastoral world with his imagination. The repetition of dashes also embodies the poet's shouting and calls: "But O, sick children of the world, of all the many changing things, in dreary dancing past us whirled, to the cracked tune that Chronos sings, Words alone are certain good".

\subsection{Arrangement of Words and Sentences}

It is not difficult to find that arrangement of words and sentences is reversed in many poems because of the need for rhyming and deliberation by poets. Different arrangement of words and sentences often leads to different results. Poetry is the art of language. Sound is not only an integral part of poetry, but also an important way to convey the meaning of poetry. One part of the language that constitutes the sound of poetry is text, which is arranged in different formats, such as lines, sections and chapters that present different visual effects to readers. This is also the embodiment of the interaction between sound and meaning in poetry. On the one hand, this poem is very cleverly arranged in the stanza. The Song of the Happy Shepherd has 57 lines and is divided into three sections. The first section is from 10 to 21 lines. The second section is from 22 to 44 and the third one is from 45 to 57 lines. It can be seen that the first two parts have the same length while the third part is relatively short. The flat narratives in the first two part make a sharp contrast with the violent bursts of emotion in the third part. These are gradually interlocking.

On the other hand, the arrangement of words in this poem is also unique. For example, in the second line, "And over is their antique joy", the preposition of the word "over" further reveals the poet's pain about the destruction of the natural environment and aversion of modern industrial civilization in which all the good things have disappeared. Therefore, readers can better appreciate this expression when they read it.

The repetition of some verses not only enhances the musical beauty of the poem, but also reflects the inseparable connection between sound and meaning. In the poem, The Song of the Happy Shepherd, "for this is also sooth" is repeated three times and "dream" and "truth" also appear many times. This repetition makes the focus of the poem more prominent. The irreconcilable contradiction between dream and reality has been emphasized in the poem through this way.

\section{CHAPTER-4 CONCLUSION}

The interaction between sound and meaning in Yeats's poems is embodied in many aspects. Through the above analysis, we can see that the sound helps this poem to coney the meaning of lamenting the destruction of nature. However, it is more preferable to analyze multiple poems to discover more interactions between sounds and meanings. Capturing and listening to the sound in poetry is of great significance for us to grasp the meaning of poetry deeply. The meaning provided by sound is only an aid and the more meaning of poetry lies in the interpretation of the text. The connection between sound and meaning also changes with different contexts. Read poetry a hundred times and see its meaning naturally. We still need to do more in-depth research in the field of sound to better understand the meaning of poetry.

\section{REFERENCES}

1. Pope, A. (1978). "An Essay on Criticism" Poems; Wadsworth Handbook and Anthology. Ed. C.F. Main\& Peter J. Seng. Belmont: Wadsworth Publishing Company.

2. Zhang, Li., Liu, Y., Wang, C. (2011). Research on ecological thoughts in Yeats's poems from images of shepherd and fisherman [J].Time Literature, 
06:173-174

3. Laurence, P. Sound and Sense: An Introduction to Poetry [M]. Harcourt.
4. Rui, Y. (2007). "Sound should be an echo of meaning"_-Research on sound and sense in English poetry [A]. Foreign Literature Studies, 5. 